\title{
Vitamin D status among infants attending Reproductive and Child Health Centre in Arusha, Tanzania; A cross-sectional study
}

Victor Zablon Urio ( $\square$ victororio21@yahoo.com )

MAKERERE UNIVERSITY

Kasirye Phillip

Mulago National Referral Hospital

Victor Musiime

Makerere University

Theresa Piloya

Makerere University

Stephen Swanson

Arusha Lutheran Medical Centre

\section{Research Article}

Keywords: Vitamin D deficiency, Infants, RCH clinic, Tanzania

Posted Date: March 9th, 2021

DOl: https://doi.org/10.21203/rs.3.rs-306783/v1

License: (9) This work is licensed under a Creative Commons Attribution 4.0 International License.

Read Full License 


\section{Abstract}

Background: Globally there is a high burden of low serum vitamin D levels, with children being more at risk, due to low intake in breastmilk, few available foods and inadequate cutaneous synthesis of vitamin D. Even in countries with abundant sunshine, Vitamin D deficiency (VDD) remains a problem. The classical clinical effect of severe vitamin D deficiency is rickets. VDD is common in developing countries and may affect developmental outcomes of children. This study aimed to determine the prevalence and factors associated with vitamin D deficiency among infants attending the Reproductive and Child Health Clinic (RCH), in Arusha, Tanzania.

Methods: This was a cross-sectional study of infants aged 6 weeks to 12 months attending RCH clinic at Arusha Lutheran Medical Centre (ALMC). We enrolled 304 infants from November 2018 to January 2019 after consent. A pre-coded questionnaire was used to collect data on sociodemographic characteristics of the infants. Physical examination was done for anthropometric measures and signs of rickets. Serum was drawn for assessment of 25-hydroxyvitamin D (25(OH) D),calcium, phosphorus, alkaline phosphate was assessed. Vitamin D deficiency was defined as $25(\mathrm{OH}) \mathrm{D}$ less than $20 \mathrm{ng} / \mathrm{ml}$. Multivariate analysis was done to determine factors associated with VDD. Statistical analysis was performed using STATA 14 version. $P$-value $<0.05$ was significant.

Results: A total of 67/ 304 infants had vitamin D deficiency. Another 50(16.5\%) were found to have insufficiency level of vitamin D. Only 187(61.5\%) had adequate vitamin D. Signs of rickets were observed in $11(3.6 \%)$ and hypocalcemia in $33(10.9 \%)$ infants.

Factors independently associated with VDD include age $<6$ months Adjusted Odds Ratio (AOR) 1.56 $(95 \% \mathrm{Cl} 1.19-4.0) \mathrm{p}$ value $<0.026$, presence of signs of rickets and hypocalcemia $\mathrm{p}$ value $<0.001$ and $<0.002$ respectively.

Conclusion and Recommendation: A high prevalence of VDD (22\%) was observed among infants attending RCH clinic in Arusha Tanzania. Age $<6$ months and the presence of the clinical sign of rickets were associated with VDD. Clinicians should actively assess for VDD and vitamin D supplementation with special emphasis infants $<6$ months should be implemented.

\section{Background}

Vitamin D deficiency is a major public health problem worldwide in all age groups, even in those residing in countries with low latitude, where it is generally assumed that ultraviolet radiation is adequate enough to prevent this deficiency $(1)$.

Humans get vitamin $D$ from exposure to sunlight, from their diet, and from dietary supplements. The most common source of Vitamin D in humans is exposure to sunlight (2) 
Globally about 1 billion people have low vitamin $D$ levels and this is found in all ethnicities and age groups with infants being at increased risk (3).

In Tanzania a study done in coastal area among infants aged 6 weeks to 6 months found that the prevalence of VDD declined from $76.4 \%$ at 6 weeks to $21.2 \%$ at 6 months(4)

The factors shown to be associated with vitamin $D$ deficiency in various studies include inadequate sun exposure, dark skin pigmentation, exclusive breastfeeding, chronic illnesses like malabsorption, medications like anticonvulsants and malnutrition(2-6).

In Arusha Tanzania, the weather is cold most of the year (7), Children are excessively swaddled during this cold season and are not exposed to the sun which can result to vitamin D deficiency $(7$,

8). Breastfeeding mothers and infants are not supplemented with Vitamin D, and infants on complimentary feeding are mainly fed on grains based with no fortification, therefore infants are predisposed to vitamin D Deficiency. Vitamin D deficiency is not routinely assessed in our setting both clinically and biochemically, despite limited vitamin $D$ supplementation.

This study aimed to provide baseline information on the prevalence and associated factors among infants attending the Reproductive and Child Health Clinic at ALMC Arusha, Tanzania and whose findings may be utilized to advocate for early intervention with supplementation amongst infants.

\section{Methods}

\section{Study design and setting}

This was a cross sectional study of 304 children attending Reproductive and Child health clinic (RCH) at Arusha Lutheran Medical Centre (ALMC), Arusha, Tanzania in the period of November 2018 to January 2019 which was a dry season. ALMC is a faith-based hospital and saves as referral hospital for the Northern Zone of Tanzania. The RCH clinic is located within ALMC; the clinic is conducted twice a week on Mondays and Thursdays for children under five years. However special cases for example those living far away from hospital, receive services when they arrive on other days. The average number of infants and toddlers attending RCH clinic are 320 per month, which includes 80 newly registered and 240 continuing children. There is no vitamin $D$ supplementation activity at the clinic to both infants and pregnant mothers. ALMC is located in the Arusha region of Tanzania, and majority of the patients who are seen in this hospital come from in and around the Arusha region. It lies at the foot of Mount Meru at 1400 metres (4600) altitude, and $-3.3^{\circ}, 36.6^{\circ}$ latitude and longitude respectively. The average annual temperature in Arusha is about 19.2 degree Celsius(9). The rainy season is from March till May and November till December. Major tribes in Arusha are Maasai and Wameru; during cold season children are overdressed with sweaters and Maasai shuka, which prevent arms and legs from exposure to sunlight resulting in a risk factor for VDD.

\section{Study participants}


Infants aged 6 weeks to 12 months attended RCH at ALMC during the study period and those whose parents gave informed consent were recruited into the study. Infants with known chronic renal disease, liver disease, those whose caretakers had inadequate information on the personal data of the infant and those who were on vitamin D supplementation were excluded. Approval to carry out this study was obtained from the School of Medicine Research and Ethics Committee, College of Health Science, Makerere University and the ALMC ethical committee.

\section{Study procedure}

The study team worked on all weekdays, Monday to Friday from $8 \mathrm{am}$ to $4 \mathrm{pm}$ as these are the working hours for RCH clinic. The team comprised of 4 research assistants ( 2 nurses and 2 medical doctors) and the principal investigator (VU). Infants aged 6 weeks to 12 months attending the RCH clinic were identified during this study period. Systematic sampling was used to enroll infants in this study. Informed written consent was obtained from the caretakers of the children. Clinical history included sociodemographic of infants and the mother, history of sun exposure, mode of feeding, dressing habit, HIV status, any other chronic illness, any use of chronic medication, growth and developmental history and history of prematurity. Good sun exposure was defined as at least $30 \mathrm{~min}$ of sun exposure at least 5 days a week between $10 \mathrm{am}$ to $4 \mathrm{pm}(10)$.

A detailed physical examination included a general exam, to look for signs of rickets such as craniotabes, widened wrist, rachitic rosary, bow legs and Harrison groove was then performed and documented, as well as a systematic examination.

Anthropometric measurements included weight in kilograms and lengths in centimeters were taken using weight scale and stadiometer respectively.

\section{Laboratory investigations}

Three milliliters of blood were drawn for serum 25 hydroxyvitamin $\mathrm{D}(25(\mathrm{OH}) \mathrm{D})$, calcium, phosphorus, alkaline phosphate, albumin, alanine transaminase and creatinine. The biochemical tests were measured using ALMC laboratory Eurolyser machines for renal function tests, electrolytes, liver function tests and Kilimanjaro Christian Medical Centre (KCMC) laboratory COBAS machine for serum 25(OH) D. Serum samples for the measurement of 25(OH) D were processed and stored at -20 degree Celsius as they waited to be measured later.

Vitamin D concentration was determined by an Elecsys immunoassay technique. This is an electrochemilumniscense immunoassay supplied by Roche diagnostics, Germany. It measures the vitamin $D$ concentrations in the range of $4-100 \mathrm{ng} / \mathrm{ml}$. The $25(\mathrm{OH}) \mathrm{D}$ level above $>30 \mathrm{ng} / \mathrm{ml}$ was considered normal, $21-30 \mathrm{ng} / \mathrm{ml}$ as insufficiency and value below $20 \mathrm{ng} / \mathrm{ml}$ as deficiency, calcium level of $8-10.5 \mathrm{mg} / \mathrm{dl}$ (2-2.6 $\mathrm{mmol}$ ) was considered normal and level of corrected calcium below $8 \mathrm{mg} / \mathrm{dl}$ as hypocalcemia, phosphorus level of $4.5-7.5 \mathrm{mg} / \mathrm{dl}(1.45-2.26 \mathrm{mmol})$ were considered normal, alkaline phosphate level > 
$410 \mathrm{IU} / \mathrm{dl}$ are considered raised, albumin less than $3 \mathrm{~g} / \mathrm{dl}$ was considered low, creatinine between 0.2 to $0.4 \mathrm{mg} / \mathrm{dl}$ were considered normal and alanine transaminase between 13-45IU were considered normal.

All children with vitamin D deficiency were put on stoss therapy of 150,000 IU then were linked in paediatric clinic for follow up.

\section{Statistical analysis}

The study was powered at $80 \%$, at an absolute error between the estimated and true value of $5 \%$ with a $95 \%$ confidence interval. We used the prevalence of vitamin D $76.4 \%$ among infants as reported by Sudfeld CR et al. in a study entitled Vitamin D deficiency is not associated with growth or the incidence of common morbidities among Tanzanian infants(4). The sample size calculated was 304.

Statistical analysis was performed using the Stata 14.0 statistical package. Continuous variables were summarized using median (interquartile range) and means (standard deviations). The prevalence of vitamin $D$ deficiency was calculated as the proportion of infants with vitamin $D$ deficiency among all those enrolled in the study. Categorical variables were compared between infants with $25(\mathrm{OH}) \mathrm{D}$ less than $20 \mathrm{ng} / \mathrm{ml}$ as deficiency versus $\geq 20 \mathrm{ng} / \mathrm{ml}$. To determine the factors associated with vitamin $D$ deficiency, logistic regression was used to determine the factors independently associated with vitamin $D$ Deficiency. Multivariate logistic regression was used to perform all variables found to have a $P$ value $\leq 0.2$ at bivariate analysis and all variable that are biologically plausible that did meet the criteria were entered in the model. Weight for length and weight for age were calculated from the WHO standard chart, $0-24$ months. A P-value less than 0.05 was considered significant.

\section{Results}

This study was conducted from $15^{\text {th }}$ November 2018 to $31^{\text {ST }}$ January 2019 , which was sunny season not as expected rain season in November of the Arusha region. Study enrollment profile is shown in figure 1.

\section{Characteristics of the study participants and mothers/caretakers.}

Table 1 shows the characteristics of the participants. The median age of the study participants was 6 month (IQR 7), with 159 (52\%) of the infants aged $\geq 6$ month. Male were 155(51\%). Majority 278 (91.4\%) were born at term with good birth. Exclusive breastfeeding was common among this population. Twentyfive (8.2 \%) of the infants were HIV exposed and eleven (3.6\%) were HIV infected. Sun exposure was good in this population $77 \%$ report good sun exposure. Seventy seven percent reported their infants to have skin exposure to sunlight.

Fifteen of the mothers (4.9\%) were on Vitamin D contains supplement and 43(14\%) are HIV infected. 


\begin{tabular}{|c|c|c|c|}
\hline \multicolumn{4}{|c|}{ Table 1; Baseline characteristics of infants and mothers/caretakers } \\
\hline \multicolumn{2}{|c|}{ Characteristics } & Frequency & Percentage \% \\
\hline \multirow[t]{2}{*}{ : } & $<6$ month & 145 & 47.7 \\
\hline & प 6 month & 159 & 53.3 \\
\hline \multirow[t]{2}{*}{$\mathrm{x}$} & Male & 155 & 51 \\
\hline & Female & 149 & 49 \\
\hline \multirow[t]{2}{*}{ ligion } & Christian & 263 & 86.5 \\
\hline & Muslim & 41 & 13.5 \\
\hline \multirow[t]{2}{*}{ stational age } & Term & 278 & 91.4 \\
\hline & Preterm & 26 & 8.6 \\
\hline \multirow[t]{3}{*}{ ants HIV status } & Negative & 268 & 88.2 \\
\hline & Positive & 11 & 3.6 \\
\hline & Seroexposed uninfected & 25 & 8.2 \\
\hline \multirow[t]{3}{*}{ pe of feeding } & Exclusive Breastfeed & 142 & 46.7 \\
\hline & Mixed/Complimentary feeding & 159 & 52.3 \\
\hline & Formula feeding & 3 & 1 \\
\hline \multirow[t]{2}{*}{.er Chronic illness* } & No & 291 & 95.7 \\
\hline & Yes & 13 & 4.3 \\
\hline \multirow{2}{*}{ ason of the month } & Rainy Season & 64 & 21.1 \\
\hline & Sunny/ Dry Season & 240 & 78.9 \\
\hline \multirow[t]{2}{*}{ n exposure $* *$} & Yes & 234 & 77 \\
\hline & No & 70 & 23 \\
\hline \multirow[t]{2}{*}{ lestone } & Uptodate & 289 & 95.1 \\
\hline & Delayed & 15 & 4.9 \\
\hline \multirow[t]{2}{*}{ ıternal religion } & Christian & 265 & 87.2 \\
\hline & Muslim & 39 & 12.8 \\
\hline \multirow[t]{2}{*}{ ıternal HIV status } & Negative & 263 & 85.9 \\
\hline & Positive & 41 & 14.1 \\
\hline
\end{tabular}

*Chronic illness; such as epilepsy, malabsorption, liver disease, kidney disease, Congenital Heart disease and Diabetes mellitus.

**Sun Exposure; was defined as atleast 15-30 min daily of exposure to sun from between 10am-3pm

\section{Prevalence of Vitamin D deficiency}

The prevalence of vitamin D deficiency was $67 / 304(22 \%)$ see figure 2 . The mean serum vitamin D level among study participants was $34.51 \mathrm{ng} / \mathrm{ml}$. Mean vitamin D deficiency level among infants was $15.53 \mathrm{ng} / \mathrm{ml}$.

Majority of the infants with Vitamin D deficiency were $<6$ months; 40 out of 67 children. 
In this study $10.9 \%$ had low calcium, $7.6 \%$ had low phosphorus, $7.9 \%$ had raised alkaline phosphatase.

Seven of the $11(63.6 \%)$ infants with low calcium, and 21 of the $24(87.5 \%)$ infants with elevated ALP had vitamin $\mathrm{D}$ deficiency.

\section{Factors associated with Vitamin D Deficiency}

Table 2 shows factors associated with vitamin D deficiency at bivariate analysis and multivariate analysis. Infant age, sun exposure, presence of clinical signs of rickets and hypocalcemia were significantly associated with Vitamin D deficiency at bivariate analysis.

However factors that are biological plausible such as prematurity, breastfeeding and HIV status were also analyzed at multivariate. At multivariate analysis factors that were independently associated with vitamin $D$ deficiency were infant age $<6$ month ( $p$ value 0.026 ), signs of rickets ( $P$ value $<0.001$ ), and hypocalcemia $P$ value $<0.048$.

Only 7 out of 67 infants with vitamin D deficiency had signs of rickets. Two out of 10 infants with severe acute malnutrition and three out of 11 infants with HIV, had vitamin D deficiency, however these were not significant both at bivariate and multivariate analysis.

Table 2; Factors associated with Vitamin $D$ deficiency at Bivariate and Multivariate analysis 


\begin{tabular}{|c|c|c|c|c|c|c|c|}
\hline \multicolumn{2}{|l|}{3} & \multirow{2}{*}{$\begin{array}{l}\begin{array}{l}\text { Not } \\
\text { deficient }\end{array} \\
132(83)\end{array}$} & \multirow{2}{*}{$\begin{array}{l}\text { Deficient } \\
27(17)\end{array}$} & \multirow{2}{*}{$\begin{array}{l}\text { OR } \\
(95 \% \mathrm{CI}) \\
1\end{array}$} & \multirow{2}{*}{$\begin{array}{l}\mathrm{P} \\
\text { value } \\
\end{array}$} & \multirow{2}{*}{$\begin{array}{l}\text { AOR } \\
(95 \% \mathrm{CI}) \\
1\end{array}$} & \multirow{2}{*}{$\begin{array}{l}\mathrm{P} \\
\text { value } \\
\end{array}$} \\
\hline & >=6month & & & & & & \\
\hline & $<6$ month & $\begin{array}{l}105 \\
(72.4)\end{array}$ & $\begin{array}{l}40 \\
(27.6)\end{array}$ & $\begin{array}{l}1.86 \\
(1.07 \\
3.23)\end{array}$ & 0.026 & $\begin{array}{l}\text { 1.56(1.19, } \\
4.0)\end{array}$ & 0.026 \\
\hline & Male & $\begin{array}{l}119 \\
(76.8)\end{array}$ & $\begin{array}{l}36 \\
(23.2)\end{array}$ & 1 & & & \\
\hline & Female & $\begin{array}{l}118 \\
(79.2)\end{array}$ & $\begin{array}{l}31 \\
(20.8)\end{array}$ & $\begin{array}{l}0.87 \\
(0.50 \\
1.50) \\
\end{array}$ & 0.611 & & \\
\hline \multirow[t]{2}{*}{ snal age } & Term & $\begin{array}{l}217 \\
(78.1)\end{array}$ & $\begin{array}{l}61 \\
(21.9)\end{array}$ & 1 & & 1 & \\
\hline & Preterm & $20(76.9)$ & $6(23.1)$ & $\begin{array}{l}1.07 \\
(0.41 \\
2.77)\end{array}$ & 0.894 & $0.93(0.3,2.9$ & \\
\hline \multirow[t]{3}{*}{ tus } & Negative & $209(78)$ & $59(22)$ & 1 & & 1 & \\
\hline & Positive & $8(72.7)$ & $3(27.3)$ & $\begin{array}{l}1.33 \\
(0.34 \\
5.17) \\
\end{array}$ & 0.682 & $\begin{array}{l}\text { 1.11 (0.38, } \\
3.29)\end{array}$ & 0.845 \\
\hline & $\begin{array}{l}\text { Seroexposed } \\
\text { uninfected }\end{array}$ & $20(80)$ & $5(20)$ & $\begin{array}{l}0.89 \\
(0.32 \\
2.46)\end{array}$ & 0.816 & $\begin{array}{l}1.13(0.27, \\
4.69)\end{array}$ & 0.866 \\
\hline \multirow[t]{2}{*}{ feeding } & Breastfeeding only & $\begin{array}{l}104 \\
(73.2)\end{array}$ & $\begin{array}{l}38 \\
(26.8)\end{array}$ & 1 & & & \\
\hline & $\begin{array}{l}\text { Mixed or } \\
\text { Complimentary } \\
\text { feeding }\end{array}$ & $\begin{array}{l}133 \\
(82.1)\end{array}$ & $\begin{array}{l}29 \\
(17.9)\end{array}$ & $\begin{array}{l}0.60 \\
(0.35 \\
1.03) \\
\end{array}$ & 0.064 & & \\
\hline \multirow[t]{2}{*}{ t Exposure } & No & $48(68.6)$ & $\begin{array}{l}22 \\
(31.4) \\
\end{array}$ & 1 & & 1 & \\
\hline & Yes & $\begin{array}{l}189 \\
(80.8)\end{array}$ & $\begin{array}{l}45 \\
(19.2)\end{array}$ & $\begin{array}{l}0.52 \\
(0.29, \\
0.95)\end{array}$ & 0.032 & $\begin{array}{l}0.6(0.31, \\
1.16)\end{array}$ & 0.129 \\
\hline \multirow[t]{2}{*}{1} & Christian & $\begin{array}{l}205 \\
(77.4) \\
\end{array}$ & $\begin{array}{l}60 \\
(22.6) \\
\end{array}$ & 1 & & & \\
\hline & Muslim & $32(82.1)$ & $7(17.9)$ & $\begin{array}{l}0.75 \\
(0.31, \\
1.78)\end{array}$ & 0.51 & & \\
\hline \multirow[t]{2}{*}{$\begin{array}{l}\text { al vitamin D } \\
\text { nent }\end{array}$} & No & $\begin{array}{l}225 \\
(77.9)\end{array}$ & $\begin{array}{l}64 \\
(22.1)\end{array}$ & 1 & & & \\
\hline & Yes & $12(80)$ & $3(20)$ & $\begin{array}{l}0.88 \\
(0.24 \\
3.21) \\
\end{array}$ & 0.845 & & \\
\hline \multirow[t]{2}{*}{ HIV status } & Negative & $\begin{array}{l}204 \\
(78.2) \\
\end{array}$ & $\begin{array}{l}57 \\
(21.8) \\
\end{array}$ & 1 & & & \\
\hline & Positive & $33(76.7)$ & $\begin{array}{l}10 \\
(23.3) \\
\end{array}$ & $\begin{array}{l}1.08(0.5, \\
2.33)\end{array}$ & 0.836 & & \\
\hline \multirow[t]{2}{*}{ signs of } & No & $\begin{array}{l}233 \\
(79.5) \\
\end{array}$ & $\begin{array}{l}60 \\
(20.5) \\
\end{array}$ & 1 & & 1 & \\
\hline & Yes & $4(36.4)$ & $7(63.6)$ & $\begin{array}{l}6.8(1.93, \\
23.98)\end{array}$ & 0.003 & $\begin{array}{l}15.63(2.9, \\
84.33) \\
\end{array}$ & 0.001 \\
\hline \multirow{2}{*}{$\begin{array}{l}\text { ed } \\
\text { lcemia }\end{array}$} & No & $233(79.5)$ & $60(20.5)$ & 1 & & 1 & \\
\hline & Yes & $4(36.4)$ & $7(63.6)$ & $\begin{array}{l}6.8(1.93, \\
23.98)\end{array}$ & 0.003 & $\begin{array}{l}2.34(1.99, \\
5.54)\end{array}$ & 0.002 \\
\hline atase & Normal & $212(76.0)$ & $67(24.0)$ & 1 & & & \\
\hline
\end{tabular}




\begin{tabular}{l|l|l|l|l|l|l|l|}
\hline & Low alkaline PH & $4(80)$ & $1(20)$ & $\begin{array}{l}0.84 \\
(0.09, \\
7.66)\end{array}$ & 0.878 & & \\
\hline & High alkaline PH & $3(12.5)$ & $\begin{array}{l}21 \\
(87.5)\end{array}$ & $\begin{array}{l}0.48 \\
(0.14, \\
1.66)\end{array}$ & 0.248 & & \\
\end{tabular}

\section{Discussion}

The prevalence of vitamin D deficiency in this study was high, at 22\% that is, 1 in 5 infants had VDD. Only $2 / 3$ of the study population was found to have optimal level of serum vitamin D. The findings can be explained by the Arusha weather, which is cold several months of the year with temperature ranging from $14.5^{\circ} \mathrm{C}$ to $19^{\circ} \mathrm{C}(7)$. With this cold weather, most infants are kept indoors and are excessively swaddled with less sun exposure which predisposes them to vitamin D deficiency $(7,8)$. However, in this study most parents reported adequate sun exposure, but it was not objectively assessed. Susanna et al was able to associate cold weather with Vitamin D deficiency(11). Majority of the infants in our study population were dark skinned, which pigmentation can hinder the conversion of vitamin D by ultra violet light in the skin. Ann Prentice et al was able to associate Vitamin D deficiency and dark skin pigmentation(12).

The prevalence obtained in our study is similar to other studies carried out in near by regions (Dar es Salaam) Tanzania and (Nairobi) Kenya. This can be explained by the fact that they had similar study population, similar weather characteristics and socioeconomic status $(4,13)$. The prevalence of Vitamin D deficiency among infants was ranging from $21.2 \%$ to $83.7 \%$ in various studies done in East Africa $(4,5$, $13,14)$.

A similar finding in a study done in Nairobi, Kenya by Nusrat on infants aged $\leq 6$ month and on exclusive breastfeeding is perhaps related to nearly similar weather characteristics as the one in our study site. Nairobi is located 1724 metres above sea level slightly higher than Arusha, which is 1400 metres above sea level(15). Both Nairobi and Arusha lie on the slopes of key mountains; mountain Kenya and Meru respectively $(15,16)$.

The discrepancy in these results compared to other studies, which found high prevalence of VDD, may be explained by age differences of study participants. Our Study had infants aged 6 week to one year, while the other studies included children less than 6 months only. In addition, the observed differences could be attributed to the fact that the studies were conducted at different times of the year and therefore the weather seasons could have been different(5). Furthermore, ALMC tends to have a more urban population that is potentially less likely to have high rates of malnutrition, a risk factor for vitamin $D$ deficiency.

Surprisingly the prevalence obtained in our study is much lower than that in a study done by Nalunkuma et al in Uganda where it is sunny throughout the year and the country is at a lower altitude than my study site. This can be explained by the fact that Nalunkuma's study used a different laboratory assay from the one I used in my study, and also her study included only children less than 6 months. 
While the observed prevalence of vitamin D deficiency in my study was high, at $22 \%$, it was less than what was expected. This can be explained by the dry season in which the study was done (this was November to January) as well as the fact that most of the infants that participated in the study were born during dry and hot seasons. During this time sun-exposure may be sufficient as a source of vitamin D. however the findings obtained were similar to those in studies done in the nearby regions.

In this study the factors that were significantly associated with VDD among the study participants included age of the infants, clinical signs of rickets and hypocalcemia. Infants who are older than 6 months were less likely to have VDD. This could be explained by the increase in physical activity above 6 months of age such as crawling that may increase the chances of sun exposure, but also they often will have started complementary feeds which are more likely to be an additional source of vitamin D. Ziegler et al also observed low rates of vitamin D deficiency among older children(17).

The commonly used complementary feeds among these infants included; eggs, porridge with vitamin D containing margarine and fish oils. The commonly used formula milk was Lactogen and NAN both of which contain adequate Vitamin D levels for daily intake(18). These could be the other reasons to explain why infants on complimentary milk and formula milk were less likely to develop VDD. Other studies reported similar findings. Gordon $\mathrm{CM}$ et al in a study among infants on breastfeeding had more than 10 fold increases risk of VDD compared to those who were on exclusive formula feeding(11).

Younger infants appeared more likely to have Vitamin D deficiency and may be explained by significant number of them being exclusively breastfed(17). Breast milk has low level of vitamin D yet mothers in Arusha are not supplemented with Vitamin D and plausibly they could also be low in Vitamin D. Said N et al made similar observations associating vitamin D deficiency with age less than six month and exclusive breastfeeding(13).

In addition, younger infants have less cutaneous synthesis of vitamin $D$ and are likely to have received minimal transplacental transfer of vitamin D. Gordon C, Sudfeld C, and Nalunkuma Cissy were also able to associate vitamin $\mathrm{D}$ deficiency with age $(4,5,11)$.

In our study, only 2 participants less than 6 months were on formula milk. This made it difficult to assess, if formula milk reduces the risk of vitamin $D$ deficiency because of the inadequate sample size. However Gordon et al reported infants on fortified formula milk to have adequate vitamin D level thereby highlighting its protective effect on $\operatorname{VDD}(11)$.

Infants with signs of rickets usually tend to have a low level of Vitamin $<10 \mathrm{ng} / \mathrm{ml}$. Therefore finding in our study that infants who had signs of rickets also had VDD is not surprising. These signs could have arisen as evidence rather than a cause of VDD. Holick MF et al made similar observations Holick MF (19). Resurrection of vitamin $\mathrm{D}$ deficiency and rickets.

In our study, there were few participants (11 infants) that had signs of rickets. However, it is important to note that these signs were picked only on clinical examination and no imaging was done, however those 
patients who found to have vitamin D deficiency were referred to the Paediatrics clinic where imaging was done. The finding of few patients only 11 with features of rickets is similar to that in a study done by Piloya et al(20).

In this study, laboratory investigation such as serum calcium concentration, serum phosphate, and serum alkaline phosphate were done; only the serum calcium level association with VDD was statistically significant associated with VDD. This can be explained by the role of vitamin $\mathrm{D}$ in the metabolism of calcium; vitamin D helps maintain calcium homeostasis by increasing absorption of ionized calcium in the intestines and in bone resorption. Thus, the major physiologic function of vitamin $D$ is to maintain serum calcium and phosphorus levels within the normal physiologic range. Therefore low vitamin D Level can result in hypocalcemia. A study by Sukru Hatun et al also made similar observations between vitamin D deficiency and hypocalcemia among a cohort of Turkish children(21).

\section{Strength of the study}

This is the first study in Tanzania that measured serum vitamin D level in children aged 6 weeks to 12 months who attended RCH clinic for follow up so providing a baseline on the prevalence of vitamin $\mathrm{D}$ deficiency. This study was conducted at the $\mathrm{RCH}$ clinic in which services are free. The laboratory analysis used (electrochemilumniscense) has a good sensitivity and abroad dynamic range(22).

\section{Limitations of the study}

We obtained Information from the caregivers, which may be subject for recall and information bias. In addition, the cross-sectional study design applied may not exhaustively establish the causality. Equally we were unable to objectively assess the children's exposure to sunshine since their responses were subjective. We also did not assess the effect of dietary intake of vitamin D, and or measure the PTH levels due to the difficulty in ascertaining the vitamin $\mathrm{D}$ and calcium levels in the diet, and financial limitations for the above two issue respectively.

\section{Conclusion}

There is a high prevalence of vitamin D Deficiency (one in five) among infants attending RCH clinic at ALMC in Arusha, Tanzania. Age below 6 months, the presence of sign of rickets and hypocalcaemia were associated with underlying VDD.

\section{Recommendation}

In view of the significantly high prevalence of vitamin D deficiency at the RCH clinic at ALMC, Tanzania active assessment for vitamin $D$ deficiency and health education should routinely be done for all infants 
presenting to hospital. The Tanzania ministry of health should consider formulating a policy on vitamin $D$ supplementation in infant babies below 6 months.

\section{Abbreviations}

25(OH) D; 25 hydroxyvitamin D, ALMC; Arusha Lutheran Medical Centre; ALP Alkaline Phosphatase; ALT; Alanine Transaminase, HIV; Human Immunodeficiency Virus, KCMC; Kilimanjaro Christian Medical Centre, NICU; Neonatal intensive care unit, RCH clinic; Reproductive and Child Health clinic. WHO; World Health Organization

\section{Declarations}

\section{Ethics approval and consent to participate statement}

Approval to carry out this study was obtained from the School of Medicine

Research and Ethics Committee College of Health Sciences, Makerere University.

(REC REF 2018-159.) and ALMC IRB Committee (Rec Number N/A). Written Informed consent was obtained from the mothers of the participants.

All study procedures were done in accordance to institutional guidelines of Makerere University and ALMC, in line with good clinical practice guidelines

\section{Consent for publication}

There are no images, videos and details relating to individual persons in this

Manuscript.

\section{Competing interest}

The authors declare they have no competing interests.

\section{Funding}

ALMC NICU Fund funded this study. The funders were not involved in the design of the study, collection of data, analysis, and interpretation of results and in the writing of the manuscript.

\section{Author's contributions}

VU participated in the conception and design of the study, data collection, participated in the statistical analysis and drafting the manuscripts. KP participated in the design of the study, contributed to the interpretation of data and helped to draft the manuscript. MV participated in the design of the study, statistical analysis and helped to draft the manuscript. TP participated in the design of the study, 
contributed to the interpretation of data and helped to draft the manuscript. SS participated in the design of the study, contributed to the interpretation of data and helped to draft the manuscript. All authors read and approved the final manuscript.

\section{Acknowledgement}

We acknowledge all the caretakers and the children who participated in this study as well as the staff at ALMC Reproductive and Child Health clinic.

\section{Availability of data and material}

The original data set will be made available by the corresponding author upon request.

\section{References}

1. Palacios C, Gonzalez L. Is vitamin D deficiency a major global public health problem? The Journal of steroid biochemistry and molecular biology. 2014;144:138-45.

2. Holick MF. Vitamin D: A millenium perspective. Journal of cellular biochemistry. 2003;88(2):296-307.

3. Holick MF, Chen TC. Vitamin D deficiency: a worldwide problem with health consequences- ${ }^{-}$The American journal of clinical nutrition. 2008;87(4):1080S-6S.

4. Sudfeld CR, Manji KP, Smith ER, Aboud S, Kisenge R, Fawzi WW, et al. Vitamin D deficiency is not associated with growth or the incidence of common morbidities among Tanzanian infants. Journal of pediatric gastroenterology and nutrition. 2017;65(4):467.

5. Cissy N, Paul L, Edison M, Fox L, editors. Survey of Vitamin D Status in Breastfeeding Infants Under the Age of 6 Months Attending the Growth Monitoring Clinic at Rubaga Hospital. ESPE 2014; 2014: European Society for Paediatric Endocrinology.

6. Voortman T, van den Hooven EH, Heijboer AC, Hofman A, Jaddoe VW, Franco OH. Vitamin D deficiency in school-age children is associated with sociodemographic and lifestyle factors. The Journal of nutrition. 2015;145(4):791-8.

7. base W. Arusha weather 2019 [cited 2019 2.12.2019]. Available from: https://http://www.weatherbase.com/weather/weather.php3?s=98736.

8. TANZANIA C. CLIMATE TO TRAVEL IN ARUSHA 2018 [cited 24 AUGUST 2019]. Available from: /http://www.climatestotravel.com/climate/tanzania.

9. AGENCY TM. ARUSHA WEATHER 2019 [cited 22/2/2019]. Available from: http://meteo.go.tz/?.

10. Mediscape. What is the recommended sun exposure for production of vitamin D? 2015 [cited 2020 2019]. Available from: https://http://www.medscape.com/answers/128762-54304/what-is-therecommended-sun-exposure-for-production-of-vitamin-d.

11. Gordon SYHCM. Vitamin D deficiency in children and adolescents: Epidemiology, impact and treatment. 2008.

12. Prentice A. Vitamin D deficiency: a global perspective. Nutrition reviews. 2008;66(suppl_2):S153-S64. 
13. Said NA, Kamenwa RW, Limbe MS, Okumu MO, Macharia WM. Prevalence of vitamin D deficiency in exclusively breastfed infants at a tertiary healthcare facility in Nairobi, Kenya. Archives of endocrinology and metabolism. 2020(AHEAD).

14. Rwebembera A, Sudfeld CR, Manji KP, Duggan C, Aboud S, Fawzi WW. Prevalence and risk factors for vitamin D deficiency among Tanzanian HIV-exposed uninfected infants. Journal of tropical pediatrics. 2013;59(5):426-9.

15. WEATHER2TRAVEL. ARUSHA WEATHER IN NOVEMBER 25 JULY 2019 [25 JULY 2019]. Available from: https://http://www.weather2travel.com/november/tanzania/arusha.php.

16. weather Nh. Nairobi Weather 2019 [24 July 2019]. Available from: https://http://www.holidayweather.com/nairobi/averages/november/.

17. Ziegler EE, Hollis BW, Nelson SE, Jeter JM. Vitamin D deficiency in breastfed infants in lowa. Pediatrics. 2006;118(2):603-10.

18. NESTLE. Lactogen 2018 [23/3/2019]. Available from: http://www.mall.coimbatore.com/heathdrinks/nestlelactogenpowder-1.html.

19. Holick MF. Resurrection of vitamin D deficiency and rickets. The Journal of clinical investigation. 2006;116(8):2062-72.

20. Piloya T, Odongkara B, Were EM, Ameda F, Mworozi E, Laigong P. Nutritional rickets among children admitted with severe pneumonia at Mulago hospital, Uganda: a cross-sectional study. BMC pediatrics. 2018;18(1):1-7.

21. Hatun S, Ozkan B, Orbak Z, Doneray H, Cizmecioglu F, Toprak D, et al. Vitamin D deficiency in early infancy. The Journal of nutrition. 2005;135(2):279-82.

22. Arneson WL, Arneson DL. Current methods for routine clinical laboratory testing of vitamin $D$ levels. Laboratory Medicine. 2013;44(1):e38-e42.

\section{Figures}






Figure 1: Showing the study profile of infants enrolled

Figure 1

STUDY PROFILE 


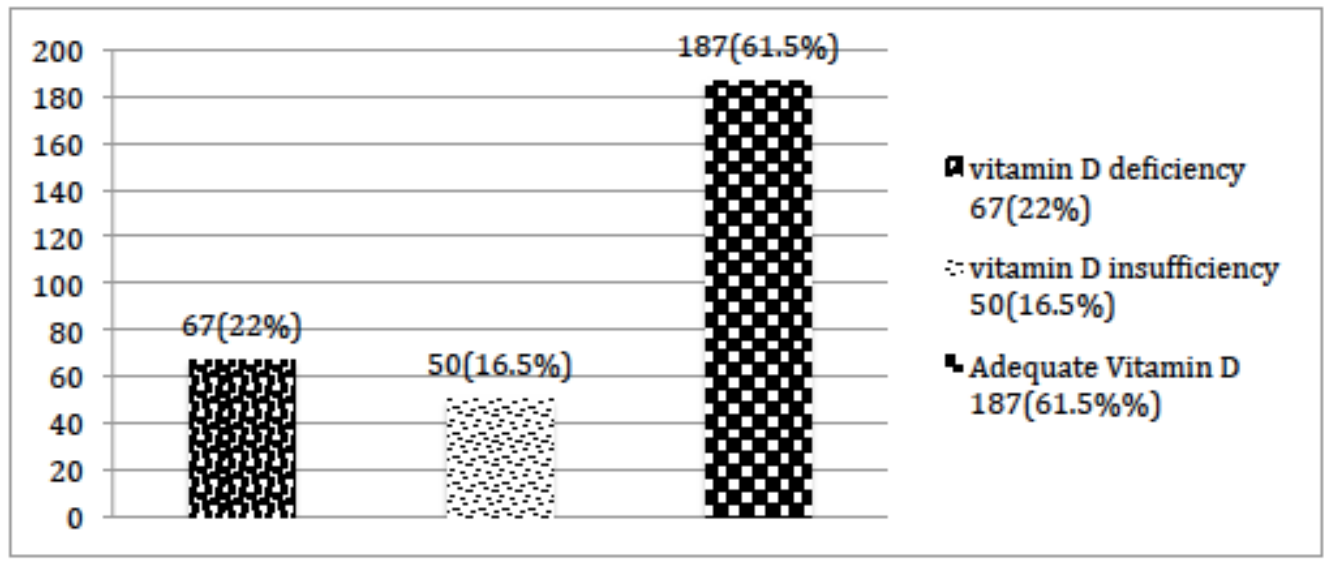

Figure 2: Bar graph showing vitamin D status of the participants

Figure 2

FIGURE SHOW PREVALENCE OF VITAMIN D STATUS

\section{Supplementary Files}

This is a list of supplementary files associated with this preprint. Click to download.

- victorscleandataset.xls

- CONSENTFORM.docx

- CONSENTFORM.docx 